\title{
Experimental Study on the Effect of Air Pollution Caused by Methane-Air Deflagration Characteristics
}

\author{
BIN ZHANG*, WEIDONG FENG, XINGDONG ZHANG, SHUDONG AN, AMANUEL \\ GIRMA, WANQING WU \\ Marine Engineering College, Dalian Maritime University, Dalian, 116026, China
}

\begin{abstract}
In order to study the effect of combustible gas cloud releasing from FPSO upper deck facilities deflagration characteristics on air pollution, a semi-open open test pipe system was built. By changing the initial conditions such as the obstacles length, distance between obstacles, section shape of obstacles and pipe system structure, the flame propagation mechanism and overpressure changing rules of methane / air deflagration were analyzed. As a result of that, the degree of sufficiency of methane combustion was analyzed, which could be seen as air pollution level. With the increase of the length of obstacle and decrease of the distance between obstacles, the induced turbulence increased, the compression effect of unburned gas became stronger, the combustion of combustible gas became more intense and sufficient, and the flame propagation speed and the maximum overpressure increased. The effect of square cross section was more obvious on inducing turbulence than that of rectangular cross section and circular cross section. The flame front was divided into many small flames by the pipe structure obstacle, and the flame front showed as a "spiny" shape. Under the effect of "spiny" flame, the methane combustion was more sufficient, and the maximum overpressure value was 3.1 times of the circular section obstacle condition. In conclusion, as the methane-air deflagration becoming more serious, although the overpressure and flame speed would be higher and the extent of damage to the surrounding facilities would be more serious, the air pollution causing by unburned gas would abate.
\end{abstract}

Keywords: air pollution, deflagration, flame propagation, overpressure changing rule

\section{Introduction}

With the increasingly change of marine environment, the trend of offshore oil and gas development is gradually developing to the deep sea and open sea. The laying cost of oil and gas return pipeline is higher and higher, and the risk is also higher and higher. Combustible gas deflagration is the biggest safety hazard in the process of FPSO (Floating Production Storage and Offloading) operation. If the accident takes place, it will not only have destructive effects on the surrounding facilities, but it may also cause air pollution. Due to the complicated arrangement of equipment, pipeline and steel frame structure on the upper deck of FPSO, which act as obstacles, the deflagration accident of combustible gas cloud on the upper deck of FPSO is always seen as a constrained deflagration accident in open space. As a result of that, by analyzing effect of the obstacle setting conditions on the characteristics of deflagration and sufficiency of combustion, the influence rules of deflagration accident on surrounding facilities and air pollution can be obtained.

Some researchers have carried out experimental and numerical study on the explosion accident of combustible gas cloud on the FPSO. Jin [1] measured the temperature failure curve of offshore engineering steel frame structure by experimental method, provided theoretical basis for the consequence analysis of offshore engineering fire and explosion accident. Park [2] and Yang [3] simulated the fire and explosion process of offshore platform by CFD (Computational Fluid Dynamics) method, and explored the impact of explosion overpressure and flame propagation on personnel and equipment. Aljaroudi [4] identified the risk of offshore platform crude oil pipeline based

*email:zhang.b231@yahoo.com,zhangbindlmu@hotmail.com 
on the leakage detection system, obtained the main risk of crude oil pipeline failure, and quantitatively analyzed the risk of operation life on crude oil pipeline failure. Heo [5] used the probability risk assessment method to predict explosive load of the associated gas leaking from the offshore platform. Because of the poor repeatability of the deflagration experiment in open space, it is not easy to analyze mechanism of the flame propagation and the law of change of overpressure. Therefore, most of the researchers conducted analysis of the mechanism of the obstacles in the process of flame propagation and evolution through combustible gas deflagration experiments in the semi open space. Wen [6] studied that the overpressure value generated when the angle of $90^{\circ}$ between the obstacles and the inner wall of the pipeline is the largest in the same obstacle length with different obstacles angles. For the obstacles with the same angle, the larger the blocking rate, the lower the maximum flame speed

Lin [7] experimentally researched on the effect of different bifurcation angles on premixed methane air explosion overpressure in pipes, the peak overpressure evolution in pipes exhibited a downward trend before the bifurcation, a sharp increase after the bifurcation until reaching the maximum, and it also found that gas explosion propagation was affected by the joint action of turbulence induced by obstacles and the abrupt increase of the cross-sectional area. Kim [8] studied the flame behavior and blast waves during unconfined hydrogen deflagrations. In unconfined areas, the results demonstrated that the overpressure rapidly increased with time. The burning velocity acceleration was greatly enhanced with spontaneous-turbulization. Patel [9] experimentally studied premixed turbulent combustion in a semi-confined explosion chamber, the experiment showed that the turbulence stretch dominated in regions behind the obstacles due to the presence of highly recirculating zones while the mean flamelet stretch was dominant in the flow jetting regions around the obstacles. Chen [10] studied the effects of the plate with different slit number on gas explosions by experiment and LES (Large Eddy Simulation), showed that the plate slits in a closed tube can result in flame acceleration of premixed methane/air [11-28].

Fairweather [29] researched flame propagation in a number of small-scale, cylindrical vessels by experimental and theoretical ways, showed that the flame propagation through the vessels, up until flame front venting, was found to be substantially laminar, with significant overpressure only being generated in the later stages of explosions due to rapid turbulent combustion in the shear layers and recirculation zones induced by the obstacles. Yu [30] researched the influence of staggered obstacles on gas explosion, compared to parallel obstacles, the experimental results showed that the flame shape was distorted significantly by staggered obstacles, and the flame propagation speed and explosion pressure were higher. Yu [31] also researched experimentally the effects of the hollow-square obstacle on gas explosion characteristics in the same blockage ratio, the triangular hollow-square obstacle was found to cause the highest flame turbulence intensity, flame propagating velocity, and explosion overpressure, whereas the circular hollow-square obstacle yielded the lowest values. Hall [32] studied the effects of the number and location of solid obstacles on the rate of propagation of turbulent premixed flames, it is found that while the peak overpressure increases with increasing number of grids or baffle plates, a limit was reached where the pressure started to decrease. The location of the obstacles was found to have a significant effect on the overpressure and the flame structure. Johansen [33] studied the effect of blockage ratio on the early phase of the flame acceleration process in an obstructed square cross section channel, it was determined that flame acceleration is more pronounced for higher blockage obstacles during the initial stage of flame acceleration up to a flame velocity below the speed of sound of the reactants. Li [34] studied the effects of obstacle distance from ignition point, the blockage ratio of obstacle and the separation distance of obstacles on the characteristics of gasoline-air mixture explosions in a semi-confined organic glass pipe. Zheng [35] studied the effect of ignition position and equivalence ratio on the characteristics of premixed hydrogen/air explosions. Wang [36] studied the effect of concentration and obstacles on methane-air mixture deflagration to detonation transition, showed that a high number of obstacles in the duct can increase flame turbulence and lead to flame acceleration [20-28]. 
It can be seen from the existing research results that some researchers have carried out experimental and numerical study on the deflagration of combustible gas cloud in the obstacle semi open space, and analyzed the change rule of flame speed, flame shape and overpressure. But there are also some outstanding problems, such as (1) The experimental conditions are not uniform, and the conclusions are hard to compare; (2) The coupling effect of the shape of obstacles and distance between the obstacles on the deflagration consequence have not been analyzed; (3) The effect of pipeline structure obstacle on the deflagration consequence have not been analyzed. In the view of these, a semi open visual experimental platform is built to simulate the coupling effect of the obstacle shape and spacing and pipeline structure obstacle on the consequence of combustible cloud deflagration. By analyzing the consequences, the flame and overpressure changing rules can be gotten, and the influence rules of deflagration accident on surrounding facilities and air pollution can be obtained. It can be used as the experimental and theoretical basis for quantitative risk assessment of combustible cloud deflagration accidents on FPSO.

\section{Materials and methods}

\subsection{Experimental Apparatus}

The experimental system mainly consists of five parts: cylindrical Plexiglas test pipe, ignition device, data acquisition system, synchronizing trigger and gas mixing system (Figure 1). The cylindrical Plexiglas test pipe is with inner diameter of $160 \mathrm{~mm}$, wall thickness of $10 \mathrm{~mm}$, and length of $600 \mathrm{~mm}$, placed horizontally, with a total volume of $12.06 \mathrm{~L}$. The opening on one side of the test pipe is used to release the high temperature gas in the experiment. A threaded hole is opened on the other side of the pipe to install the spark plug of the ignition device, which is composed of spark plug and ignition controller. The ignition voltage is $60 \mathrm{~V}$. The ignition energy is $100 \mathrm{~mJ}$. The data acquisition system consists of pressure sensor, data acquisition card, data acquisition case and PC. It adopts PPM$127 \mathrm{H}$ pressure sensor with exposed diaphragm, the measurement range is $-5 \sim 5 \mathrm{kPa}$, the response time is $2 \mathrm{~ms}$, and the accuracy grade is 0.5 . The data acquisition card uses the American Ni 9234 acquisition card, and the $10 \mathrm{kHz}$ sampling rate is used in the experiment. NI 9178 case is used as the data acquisition case, which transmits the collected data to the computer. The high-speed camera used for flame dynamic acquisition is Phantom V.2012, with a full resolution of $1280 \times 800$. Because the flame propagation speed in the pipe is fast, the shooting speed used in the experiment is $3000 \mathrm{fps}$. The synchronous trigger device makes the ignition device, data acquisition card and high-speed camera act simultaneously. The gas mixing system includes: premixed cylinder, digital pressure gauge, pressure reducing valve, vacuum pump and stop valves.

In the experiment, the wooden blocks of different lengths and shapes are used to simulate FPSO equipment modules, and square wire mesh is used to simulate FPSO pipe system structure. The blocking ratio is set to the same value of 0.24 . The specific experimental conditions are shown in Table 1. Based on Dalton's law of partial pressure, the premixed gas (methane and air) of $20 \%$ concentration and $1 \mathrm{MPa}$ pressure is prepared in the mixed gas cylinder $(2.24 \mathrm{~L})$. The semi-enclosed pipe is sealed off and vacuumed to $0.05 \mathrm{MPa}$. The gas from mixed gas cylinder is then introduced into the semienclosed pipe until the pressure of semi-enclosed pipe reaching $0.1 \mathrm{MPa}$, and the gas concentration in the pipe is $10 \%$. To ensure good mixing of gas, lay aside for $5 \mathrm{~min}$. After seal removal, the gas is ignited and the flame propagates from the end of igniter to the end of opening in the semi-enclosed pipe. Each experiment of the same condition is repeated 3-5 times to avoid the effects of the accidental factors and ensure result accuracy. 
a.

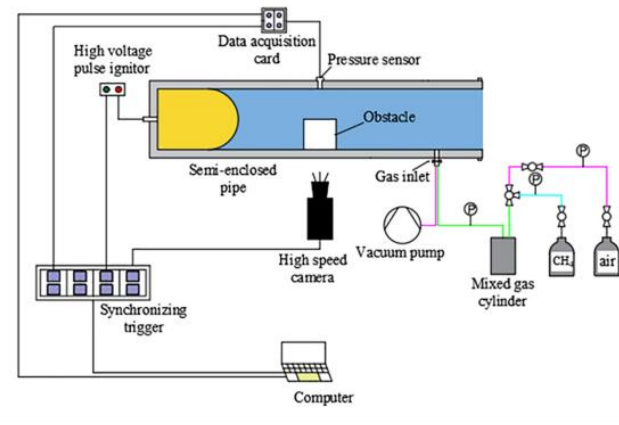

b.

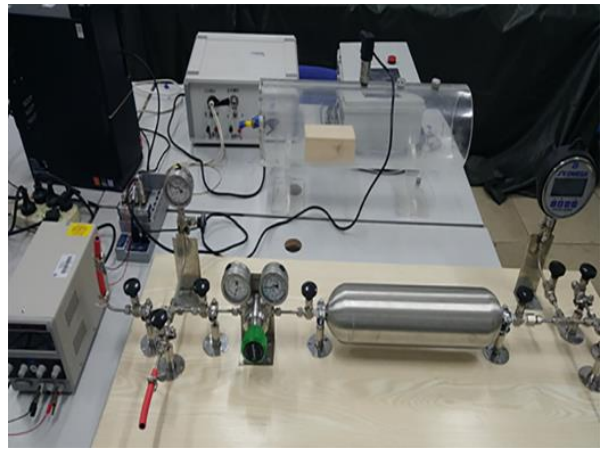

Figure 1. Experimental system diagram

(a. Schematic diagram, b. Physical diagram)

Table 1. Experimental conditions

\begin{tabular}{cccccc}
\hline Conditions & $\begin{array}{c}\text { Obstacle } \\
\text { number }\end{array}$ & $\begin{array}{c}\text { Cross-section } \\
\text { shape }\end{array}$ & $\begin{array}{c}\text { Distance between } \\
\text { obstacles(mm) }\end{array}$ & $\begin{array}{c}\text { Length } \\
(\mathbf{m m})\end{array}$ & $\begin{array}{c}\text { Distance from } \\
\text { ignition }(\mathbf{m m})\end{array}$ \\
\hline Condition 1 & 1 & Circular & NA & 30 & 100 \\
Condition 2 & 1 & Circular & NA & 60 & 100 \\
Condition 3 & 1 & Circular & NA & 100 & 100 \\
Condition 4 & 2 & Circular & 80 & $120 \& 30$ & 100 \\
Condition 5 & 2 & Circular & 160 & $120 \& 30$ & 100 \\
Condition 6 & 2 & Circular & 240 & $120 \& 30$ & 100 \\
Condition 7 & 2 & Rectangular & 160 & $120 \&$ d30 & 100 \\
Condition 8 & 2 & Square & 160 & $120 \& 30$ & 100 \\
Condition 9 & 1 & Mesh & NA & 100 & 100 \\
Condition 10 & 1 & Mesh & NA & 100 & 300 \\
Condition 11 & 1 & Mesh & NA & 100 & 500 \\
\hline
\end{tabular}

\section{Results and discussions}

\subsection{Effect of obstacle length}

It can be seen from Figure 2, that with the increase of the obstacle length, the time used for the flame front to reach the opening side of test pipe is gradually shortened. Because with the increase of obstacles length, the flame propagation time on the obstacles increases, which makes the unburned gas in front of the flame compress more fully, the ambient temperature and pressure of unburned gas increase. After passing the obstacle, under the effect of induced turbulence, the downward entrainment becomes stronger and the combustion of premixed gas becomes more intense and sufficient, which will lead to more serious damage but less air pollution (less unburned gas escape into air). It can be seen from Figure 3, compared with condition 1, the peak value of overpressure in condition 3 and 2 is respectively increased by $51.92 \%$ and $23.08 \%$.
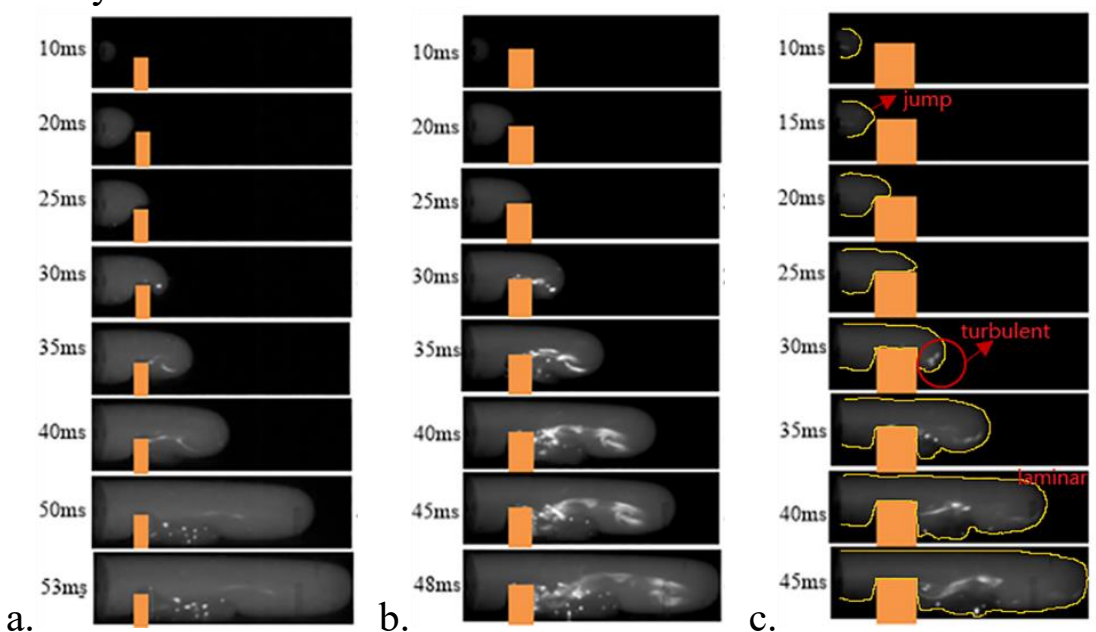

Figure 2. Flame propagation images under different obstacle length 
(a. condition 1, b. condition 2, c. condition 3)

a.

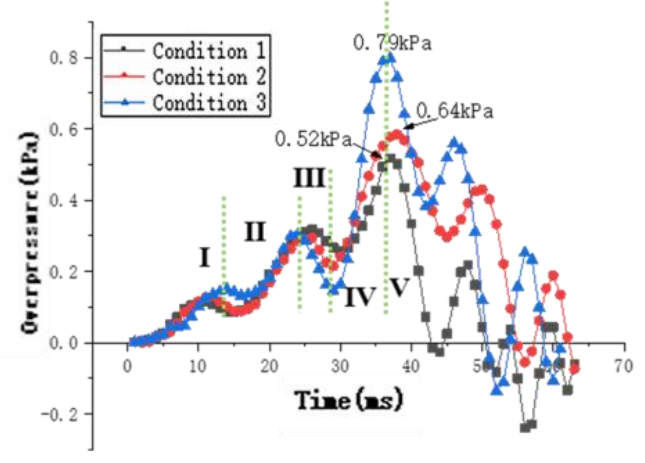

b.

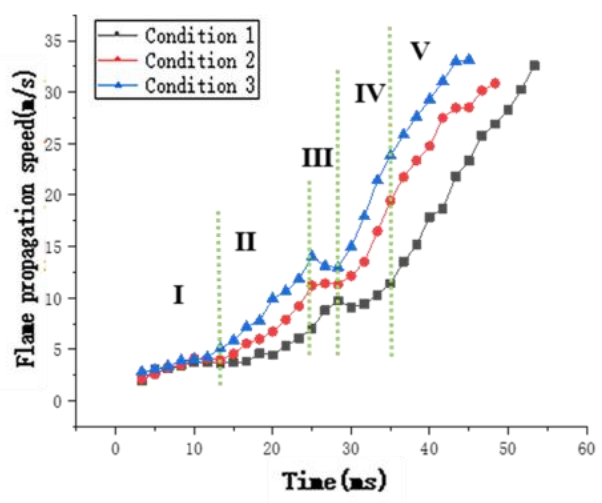

Figure 3. Characteristic curves of different obstacle length

(a. overpressure, b. flame propagation speed)

Taking the condition 3 as an example, which is with the maximum overpressure and the fastest flame propagation speed, it can be seen from Figure $2 \mathrm{c}$ and Figure 3 that, the flame propagation process can be divided into five stages. In the first stage (before $14 \mathrm{~ms}$ ), before the flame reaching the obstacle, the flame front propagates in the form of "fingers", mainly laminar flow, and the flame speed and overpressure value increase slowly; in the second stage (14-24 ms), the flame front jumps and stretches on the obstacle, and the overpressure value and flame speed increase faster than the first stage; in the third stage (24-30 ms), the flame front shows obvious entrainment, and overpressure value and flame speed decrease obviously; in the fourth stage $(30-35 \mathrm{~ms})$, overpressure value and flame speed increase rapidly, and the flame front shows turbulent propagation; in the fifth stage ( after 35 $\mathrm{ms}$ ), the flame front resumes "finger" propagation again, and the flame speed continued to increase until the shock wave reaches the open side of pipe before the flame, at the same time the overpressure value fluctuates in a large range.

\subsection{Effect of distance between the two obstacles}

Comparing Figure 4, it can be found that when the flame crosses the first obstacle and reaches the second obstacle, the flame undergoes the change process of turbulence-laminar -turbulence. With the increase of the distance between the obstacles, the brightness of the flame decreases, that means the combustion being more insufficiently. But the development of the laminar flow process is more sufficient, which would lead to turbulence intensity decrease after passing through the first obstacle. As a result of that, the secondary turbulence induced by the second obstacle would be more weaken. The second obstacle is shorter than the first one, which makes the effect of enhancement on flame front turbulence less than the first one. The evidences can be provided by Figure 5, the maximum overpressure value decreases by $16.2 \%$ and $3.7 \%$ and the flame front propagation speed decreases by $16.7 \%$ and $4.5 \%$ respectively with the increase of distance between the obstacles. 

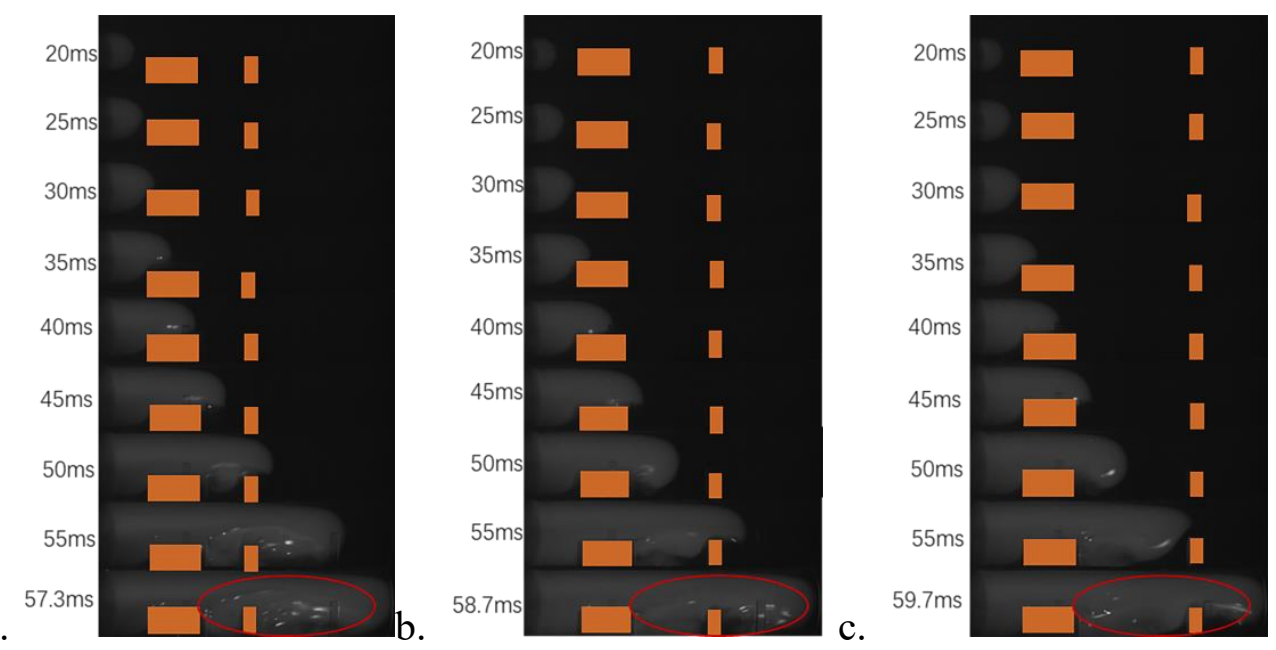

Figure 4. Flame propagation images of circular section obstacles (a. condition 4, b. condition 5, c. condition 6)
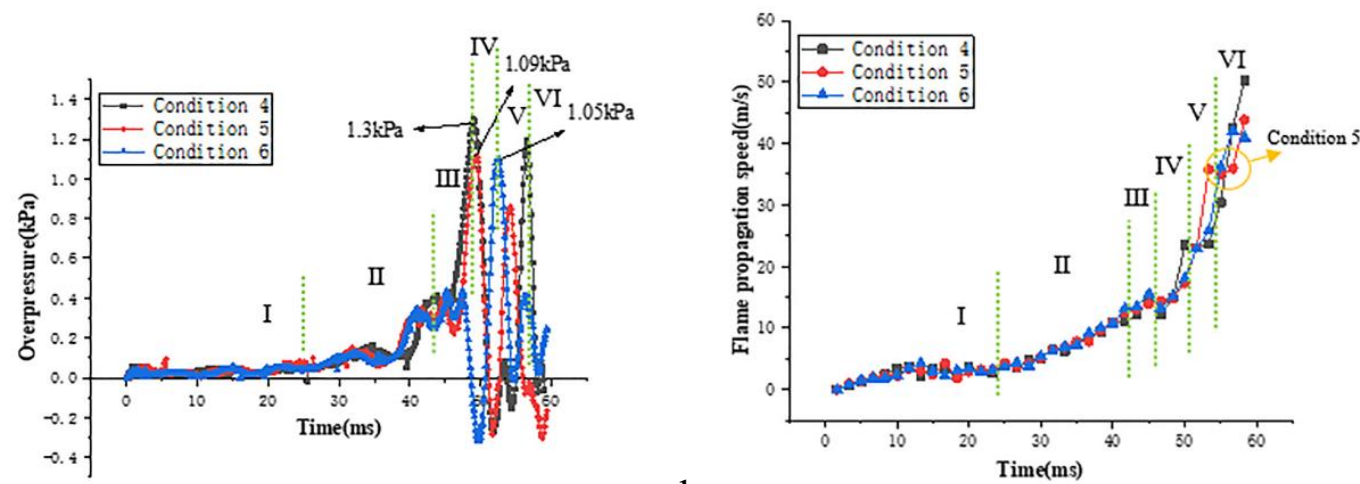

b.

Figure 5. Characteristic curves of circular section obstacles

(a. overpressure, b. flame propagation speed)

Taking the condition 4 with the maximum overpressure and the fastest flame propagation speed as an example, by analyzing Figure $4 \mathrm{a}$ and Figure 5, the flame propagation process can be divided into six stages. In the first stage (before $27 \mathrm{~ms}$ ), the flame front propagates in the form of "finger", mainly laminar flow, and the overpressure value and flame front speed increase slowly; in the second stage ( $27-44 \mathrm{~ms}$ ), the flame propagates on the first obstacle with the length of $120 \mathrm{~mm}$, and is stretched by the narrow space between the first obstacle and pipe, mainly turbulent flow. The overpressure value and flame front speed increase faster than in the first stage; in the third stage (44-47 ms), the flame crosses the first obstacle, the flame front shows obvious entrainment, and the overpressure value and flame speed decrease obviously. In the fourth stage $(47-50 \mathrm{~ms})$, the overpressure value and flame speed increase rapidly, and the flame front showed turbulent propagation; in the fifth stage (50-54 ms), under the joint action of the flame propagation dominated by turbulence and the second obstacle, the induced turbulence is strengthened, and the flame presents the same regular of the third $\sim$ the fourth stage again. However, due to the shorter length of the second obstacle and the smaller enhancement of turbulence, two obvious pressure wave peaks appear, and the pressure value of the first wave peak is higher. Compared with condition $5(53-57 \mathrm{~ms})$, the deceleration process in the fifth stage of condition 4 is not as obvious as that in condition 5 , which indicates that on the effect of decreasing the distance between obstacles, the turbulent intensity and the time of flame acceleration are both increased. As a result of that, the combustion intensity is enhanced. In the sixth stage (after $54 \mathrm{~ms}$ ), the flame front tends to resume "finger" propagation. The flame speed continues to increase until the shock wave reaching the open side of pipe before the flame, which makes the overpressure value fluctuating in a large range. 


\subsection{Effect of obstacles section shape}

Comparing Figure 6, it can be found that influence of obstacles with different section shapes on flame propagation is similar, but the intensity of effect is different. In the case of the same blocking rate, the effect of turbulence induced by square cross section (condition 8) is more obvious, as shown in Figure 7, the intensity of entrainment and deceleration after passing the first obstacle is bigger than rectangular cross section (condition 7) and circular cross section (condition 5), which the flame speed is $1.86 \%$ lower than condition 7 and $1.68 \%$ lower than condition 5 , however, while the acceleration of flame front after passing the first obstacle is $40.4 \%$ higher than condition 7 and $53.1 \%$ higher than condition 5, respectively, and the maximum overpressure is $4.5 \%$ lower than condition 7 and $13.8 \%$ lower than condition 5 . The evolution of flame propagation over the second obstacle is similar to that of the first obstacle, but the effect of the second obstacle on the entrainment deceleration and turbulence enhancement is more obvious, which will lead to more serious damage and weaken air pollution. The flame speed of condition 8 is $14.4 \%$ lower than that of condition 7 and $16.6 \%$ lower than condition 5 after passing the second obstacle and the flame speed acceleration is $13.5 \%$ and $60.5 \%$ higher respectively.
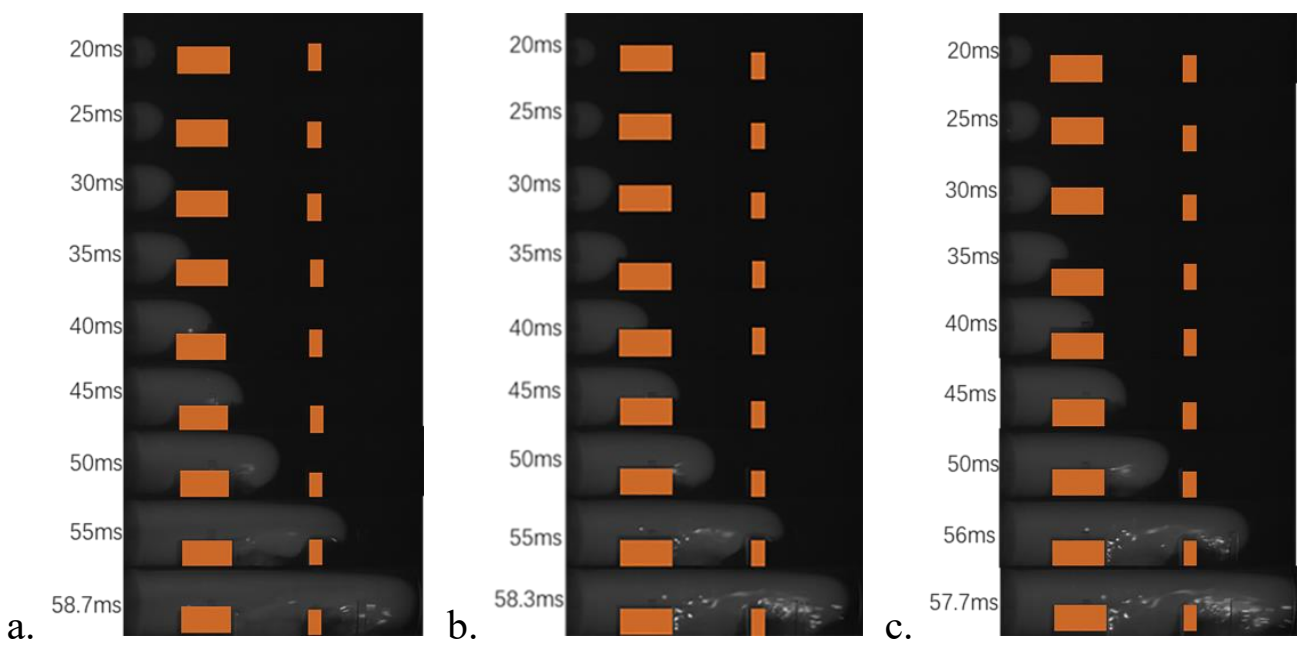

Figure 6. Flame propagation images of different obstacles section shape (a. condition 5, b. condition 7, c. condition 8)

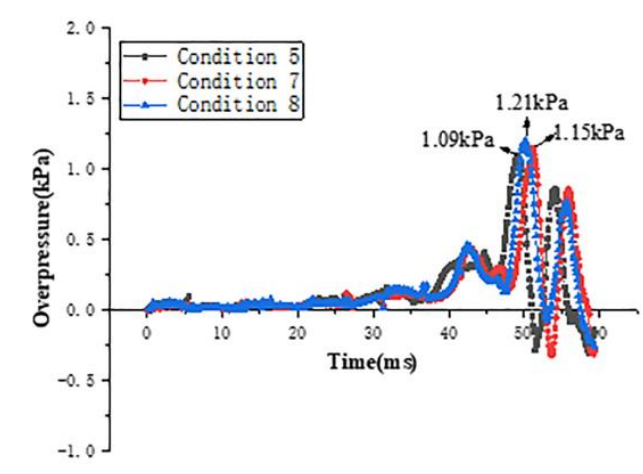

a.

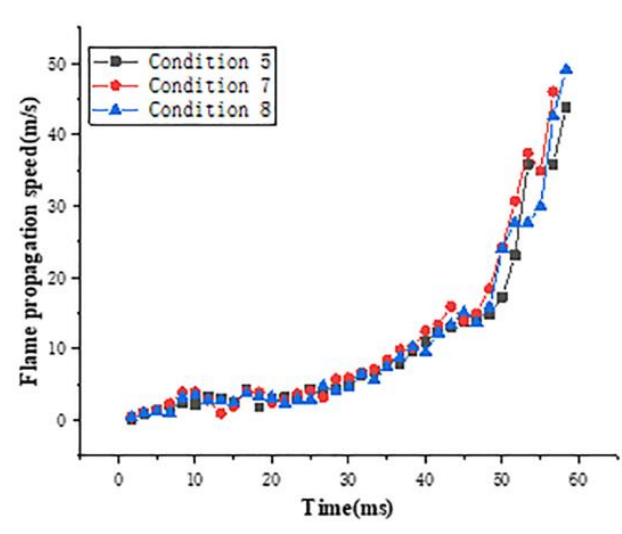

b.

Figure 7. Characteristic curves of different obstacles section shape (a. overpressure, b. flame propagation speed)

It is due to the narrow space between the upper surface of obstacle and pipe wall of condition 8 is less than that of condition 7 and condition 5, the compression effect of the pressure wave ahead of the flame passing through the obstacle on the unburned gas is stronger, and the turbulence enhancement is more obvious. However, the narrow space between the upper surface of obstacle and pipe wall of 
condition 5 is smaller than that of condition 7, the maximum overpressure value and flame speed is lower than that of condition. Because the text pipe is a cylindrical pipe, when the "finger" flame front passes through the circle narrow space (condition 5), the effect of stretching flame, compressing unburned premixed gas and turbulence enhancement is much more weaken than the channel which is $90^{\circ}$ to pipe wall forming under the Condition 7.

\subsection{Effect of pipe structure}

The size of pipe structure obstacle is $100 \mathrm{~mm} \times 100 \mathrm{~mm} \times 100 \mathrm{~mm}$, the number of vertical and horizontal wire mesh on each surface is 13 , and the blocking rate is 0.24 . It can be seen from Figure 8 and Figure 9 that with the increase of distance from igniter, the maximum overpressure value and flame propagation speed increase. The maximum overpressure value of condition 9 compared with condition 10 and 11 decrease by 53.9 and $26.1 \%$ respectively. That means that with the increase of the distance from the ignition source, the effect of the pipe structure on turbulence enhancement and flame stretch is weakened.

Taking the condition 9 with the maximum overpressure and the fastest flame propagation speed as an example (Figure 8a and Figure 9b), the flame propagation process can be divided into five stages. In the first stage (before $25 \mathrm{~ms}$ ), the flame front propagates in the form of "finger", mainly laminar flow, and the overpressure value and flame front speed increase slowly; in the second stage (25 ms-35 $\mathrm{ms}$ ), the flame front contacts the pipe structure obstacle, and is divided into many small flamelet, at the same time, the flamelet is stretched, and the flamelet front propagation acceleration becomes higher; in the third stage ( $35 \mathrm{~ms}-43 \mathrm{~ms}$ ), the flamelet passes through the pipe structure obstacle, and the flamelet front spreads forward in a "spiny" way, under the effect of that, the methane combustion was more sufficient. At $39 \mathrm{~ms}$, the overpressure value and flamelet speed reach the maximum value at $2.45 \mathrm{kPa}$ and $39 \mathrm{~m} / \mathrm{s}$ relatively; in the fourth stage $(43 \mathrm{~ms}-47 \mathrm{~ms}$ ), the flamelet front is sucked and decelerated, and the "spiny" small flamelet converges to the center line, which changes the shape of flame. The flame front gradually changes from turbulent flow to "finger" laminar flow; in the fifth stage (after 47 $\mathrm{ms}$ ), the flame front tends to resume "finger" propagation, the flame speed continued to increase until the shock wave reaches the open side of pipe before the flame, and the overpressure value fluctuates in a large range, and the flame reaches the open side of pipe at $50 \mathrm{~ms}$.
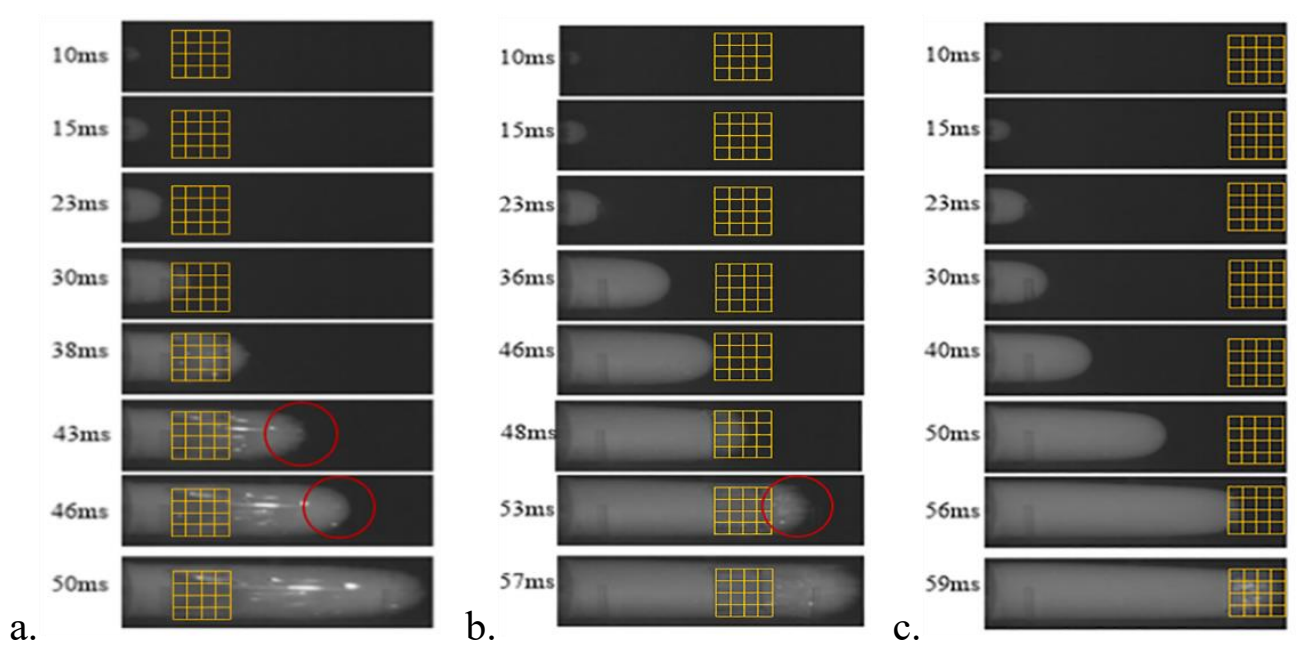

Figure 8. Flame propagation images of different distances between pipe structure obstacle and igniter (a. condition 9, b. condition 10, c. condition 11) 


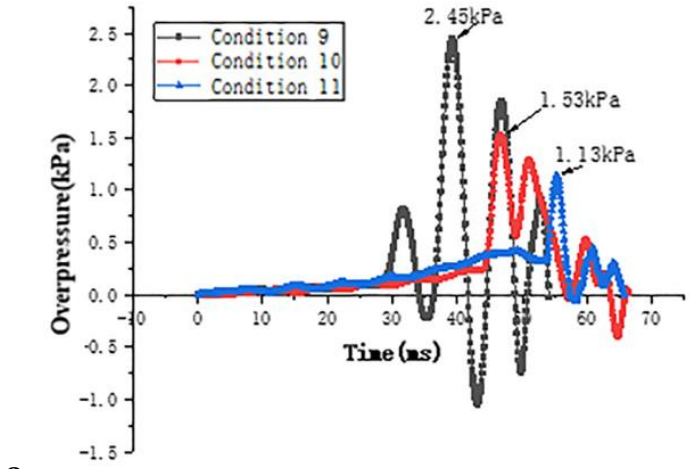

a.

Figure 9. Characteristic curves of different distances between pipe structure obstacle and igniter (a. overpressure, b. flame propagation speed)

Comparing with Figure $3 \mathrm{a}$ and Figure $9 \mathrm{a}$, it can be found that condition 9 increased the maximum overpressure value by $210.1 \%$ compared with condition 3 . According to the third stage shown in Figure $3 \mathrm{~b}$ and Figure $9 \mathrm{~b}$, it can be found that under condition 3, the entrainment deceleration occurs immediately after the flame crosses the obstacle, mainly due to the effect of the obstacle; while condition 9 does not occur immediately under the effect of many small turbulent flow fields spread by "spiny" flamelet, but continues to increase rapidly. When it propagates to the fourth stage, the "spiny" flamelet converges into a "finger" flame, which means much small turbulence converge into a relatively stable large eddy turbulence. The entrainment deceleration will occur under the effect of the pipe wall. It can be seen that the "spiny" flame propagation pattern under the action of structural obstacles in the piping system is the performance of numerous small turbulent flow fields inside the combustible gas, its effect is to enhance the overall turbulence intensity, increase the contact area with the unburned gas, make the chemical reaction more intense, and greatly increase the maximum overpressure value and flame propagation speed, which leads to more serious damage but less air pollution.

\section{Conclusions}

In order to study the effect of combustible gas cloud releasing from FPSO upper deck facilities deflagration characteristics on air pollution, a semi-open open test pipe system is built. By changing the initial conditions such as the obstacles length, distance between obstacles, section shape of obstacles and pipe system structure, the influence rules of deflagration intensity are obtained, which can provide the evidences to explain the air pollution causing by unburned gas. The main conclusions are as follows:

(1) With the increase of the length of obstacles, the effect of induced turbulence is enhanced, the compression effect of unburned gas is stronger, the flame propagation speed and the maximum overpressure increase. As a result of that, the combustion is more intense and sufficient which indicates that the amount of unburned gas escaping into air decreases and the effect of air pollution causing by unburned gas abates. The maximum overpressure value of condition 3 and 2 increase by $51.92 \%$ and $23.08 \%$ respectively compared with that of condition 1 .

(2) The flame undergoes the change process of turbulence-laminar-turbulence between two obstacles. With the increase of the distance between obstacles, the turbulence between obstacles changes into laminar flow more sufficiently, which leads to turbulence intensity of flame front become weaken and the degree of air pollution is more serious. The maximum overpressure of condition 6 is $16.2 \%$ and $3.7 \%$ lower than that of condition 4 and 5 respectively, and the flame front propagation speed is $16.7 \%$ and $4.5 \%$ lower respectively.

(3) In the case of the same blocking rate, obstacles number and distance between obstacles, the minimum distance between the upper surface of the square cross section obstacle and the top wall of 
the pipe is smaller than that of the rectangular cross section obstacle, which leads to the effect of inducing turbulence be more intense and the degree of air pollution be more weaken. As a result of that, the flame propagation speed of square one is $40.4 \%$ higher than rectangular one. Although the minimum distance between the upper surface of the rectangular cross section obstacle and the top wall of the pipe is greater than that of the circular cross section obstacle, the turbulence enhancement effect is more intense. The reason is the narrow channel with $90^{\circ}$ angle forming between the rectangular obstacle and test pipe wall can induce to compress the unburned gas much higher than the approximate ring narrow channel forming in the circular one.

(4) With the increase of distance from pipe structure to igniter, the maximum overpressure value and flame propagation speed increase. The flame front contacts the pipe structure obstacle, and is divided into many small flamelet, which spreads forward in a "spiny" shape. In this process, the gas is more fully mixed with air and combustion become more sufficient. On the effect of that, less unburned gas escapes into air and causes air pollution. After $10 \mathrm{~ms}$, the "spiny" flamelet converges into a "finger" flame, which means many small turbulence flows converge into a relatively stable large eddy turbulence flow. The entrainment deceleration takes place under the effect of the pipe wall. The maximum overpressure value of this condition is 3.1 times of condition 3 (circular cross section obstacle).

Acknowledgements: National Natural Science Foundation of China (51306026); This research was financially supported by the Fundamental Research Funds for the Central Universities (3132019038) and (3132019339); Liaoning Provincial Natural Science Foundation of China (201602087).

\section{References}

1. JIN, Y. L., JANG, B. S., Probabilistic fire risk analysis and structural safety assessment of FPSO topside module. Ocean. Eng., 104, 2015, 725-737.

2. PARK, J. C., PAIK, J. K., CFD Simulation of Methane Combustion for Estimation of Fire and Explosion in Offshore Plant. J. Ocean. Eng. Technol., 27(2),2013, 59-68.

3. YANG, Z., WANG, J., Use of fuzzy risk assessment in FMEA of offshore engineering systems. Ocean. Eng., 95, 2015, 195-204.

5. HEO, Y. A., LEE, I., Parametric generation of explosion scenarios for quantitative risk assessment of gas explosion in offshore plants. Proc. Saf. Prog., 36(2),2016, 139-149.

6. WEN, X., DING, H., SU, T., WANG, F., DENG, H., ZHENG, K., Effects of obstacle angle on methane-air deflagration characteristics in a semi-confined chamber. J. Loss. Prev. Proc. Indu., 45, 2017, 210-216.

7. LIN, B. Q., GUO, C., SUN, Y. M., ZHU, C. J., YAO, H., Effect of bifurcation on premixed methane-air explosion overpressure in pipes. J. Loss. Prev. Proc. Indu., 43, 2016, 464-470.

8. KIM, W. K., MOGI, T., DOBASHI, R., Flame acceleration in unconfined hydrogen/air deflagrations using infrared photography . J. Loss. Prev. Proc. Indu., 26(6), 2013, 1501-1505.

9. PATEL, S. N. D. H., IBRAHIM, S. S., YEHIA, M. A., HARGRAVE, G. K., Investigation of premixed turbulent combustion in a semi-confined explosion chamber. Exp. Therm. Fluid. Sci., 27(4), 2003, 355-361.

10. CHEN, P., LUO, G., SUN, Y., LV, Q., Effects of plate slits on flame acceleration of premixed methane/air in a closed tube. J. Energy. Inst., 91(4), 2017, 563-572.

11.GU, F., GUO, J., YAO, X., SUMMERS, P. A., WIDIJATMOKO, S. D., HALL, P., An investigation of the current status of recycling spent lithium-ion batteries from consumer electronics in China. J. Clean. Prod., 161, 2017, 765-780.

12.ZHU, B., SU, B., LI, Y., Input-output and structural decomposition analysis of India's carbon emissions and intensity, 2007/08-2013/14. Applied Energy, 230, 2018, 1545-1556.

13.GUO, J., ZHANG, X., GU, F., ZHANG, H., FAN, Y., Does air pollution stimulate electric vehicle sales? Empirical evidence from twenty major cities in China. J. Clean. Prod., 249, 2020, 1-31. 
14.JI, Q., GUO, J. F., Oil price volatility and oil-related events: An Internet concern study perspective. Appl. Energy., 137, 2015, 256-264.

15.GU, F., MA, B., GUO, J., SUMMERS, P. A., HALL, P., Internet of things and Big Data as potential solutions to the problems in waste electrical and electronic equipment management: An exploratory study. Waste. Manage., 68, 2017, 434-448.

16.ZHANG, T., WU, X., SHAHEEN, S. M., ZHAO, Q., LIU, X., RINKLEBE, J., REN, H., Ammonium nitrogen recovery from digestate by hydrothermal pretreatment followed by activated hydrochar sorption. Chem. Eng. J., 379, 2020, 1-54.

17.ZHU, B., SU, B., LI, Y., Input-output and structural decomposition analysis of India's carbon emissions and intensity, 2007/08-2013/14. App. Energy., 230, 2018, 1545-1556.

18.ZHU, B., YE, S., JIANG, M., WANG, P., WU, Z., XIE, R., WEI, Y. M., Achieving the carbon intensity target of China: A least squares support vector machine with mixture kernel function approach. Appl. Energy., 233, 2019, 196-207.

19.LIU, X., ZHOU, X., ZHU, B., HE, K., WANG, P., Measuring the maturity of carbon market in China: an entropy-based TOPSIS approach. J. clean. Prod., 229(1), 2019, 94-103.

20.ZHU, B., ZHOU, X., LIU, X., WANG, H., HE, K., WANG, P., Exploring the risk spillover effects among China's pilot carbon markets: A regular vine copula-CoES approach. J. Clean. Prod., 242, 2020, $1-7$.

21.WANG, P., LI, J. B., BAI, F. W., LIU, D. Y., XU, C., ZHAO, L., WANG, Z. F., Experimental and theoretical evaluation on the thermal performance of a windowed volumetric solar receiver. Energy, 119, 2017, 652-661.

22.LEI, Z., GAO, H., CHANG, X., ZHANG, L., WEN, X., WANG, Y., An application of green surfactant synergistically metal supported cordierite catalyst in denitration of Selective Catalytic Oxidation. J. Clean. Prod., 249, 2020, 1-26.

23.WANG, G., WANG, F., SHEN, F., JIANG, T., CHEN, Z., HU, P., Experimental and optical performances of a solar CPV device using a linear Fresnel reflector concentrator. Renew. Energy., 146, 2020, 2351-2361.

24.WANG, Y., CAO, L., HU, P., LI, B., LI, Y., Model establishment and performance evaluation of a modified regenerative system for a $660 \mathrm{mw}$ supercritical unit running at the IPT-setting mode. Energy, 179, 2019, 890-915.

25.CAO, L., TU, C., HU, P., LIU, S., Influence of solid particle erosion (SPE) on safety and economy of steam turbines. Appl. Therm. Eng., 150, 2019, 552-563.

26.LEI, Z., JIHAO, C., ZHANG, L., HUIBIN, H., YUSU, W., YONGHUI, L., Preparation of soybean oil factory sludge catalyst and its application in selective catalytic oxidation denitration process. J. clean. Prod., 225, 2019, 220-226.

27.LEI, Z., YANG, J., HUIBIN, H., CHAO, Y., MIN, L., LINTIAN, M., Preparation of soybean oil factory sludge catalyst by plasma and the kinetics of selective catalytic oxidation denitrification reaction. J. clean. Prod., 217, 2019, 317-323.

28.YU, D., ZHU, H., HAN, W., HOLBURN, D., Dynamic multi agent-based management and load frequency control of PV/Fuel cell/wind turbine/CHP in autonomous microgrid system. Energy, 173, 2019, 554-568.

29. FAIRWEATHER, M., HARGRAVE, G. K., IBRAHIM, S. S., WALKER, D. G., Studies of premixed flame propagation in explosion tubes. Comb. Flame., 116(4), 1999, 504-518.

30.YU, M. G., JI, W. T., WEN, X. P., LI, G., Experimental study of the influence of staggered obstacles on gas explosion. J. China. Univ. Min. Technol., 2013, 42(3), 349-354.

31.YU, M., ZHENG, K., CHU, T., Gas explosion flame propagation over various hollow-square obstacles. J. Nat. Gas. Sci. Eng., 30, 2016, 221-227.

32.HALL, R., MASRI, A. R., YAROSHCHYK, P., IBRAHIM, S. S., Effects of position and frequency of obstacles on turbulent premixed propagating flames. Comb. Flame., 156(2), 2009, 439446. 
33. JOHANSEN, C. T., CICCARELLI, G., Visualization of the unburned gas flow field ahead of an accelerating flame in an obstructed square channel. Comb. Flame., 156(2), 2009, 405-416.

34. LI, G., DU, Y., LIANG, J., WANG, S., WANG, B., QI, S., Characteristics of gasoline-air mixture explosions with different obstacle configurations. J. Energy. Inst., 91, 2018, 194-202.

35. ZHENG, L., ZHU, X., WANG, Y., LI, G., YU, S., PEI, B., WANG, W., Combined effect of ignition position and equivalence ratio on the characteristics of premixed hydrogen/air deflagrations. Int. J. Hydr. Energy., 43, 2018, 430-441.

36. WANG, C., HUANG, F., ADDAI, E. K., DONG, X., Effect of concentration and obstacles on flame velocity and overpressure of methane-air mixture. J. Loss. Prevent. Proc. Indu., 43, 2016, 302310.

Manuscript received: 17.03.2020 